\title{
Comparison of UV-spectrophotometry and high- performance liquid chromatography for determination of chlorpheniramine maleate in tablet in the presence of tartrazine
}

\author{
Febri ANNURYANTI 1 (D), Fiona Lisa YULINAR 1 (D), Rosa Iftia ELFADIANA 1 (D), Isnaeni ISNAENI 1 (D), \\ Asri DARMAWATI $1 *$ iD \\ 1 Department of Pharmaceutical Chemistry, Faculty of Pharmacy, Airlangga University, Surabaya, Indonesia. \\ * Corresponding Author. E-mail: asri-d@ff.unair.ac.id (A.D.); Tel. +62-081-330 240866.
}

Received: 18 October 2019 / Revised: 23 January 2020 / Accepted: 14 February 2020

\begin{abstract}
The presence of tartrazine, yellow coloring agent, suspected to interfere with the CPM determination in CPM tablets using direct spectrophotometry or high performance liquid chromatography. Overlap spectra of tartrazine and CPM at an analytical wavelength and peak tailing were the main problem occurs in CPM tablets analysis. The aim of this study was to develop a derivative UV spectrophotometry and a modified HPLC to overcome the problem in CPM tablet analysis. Both validated methods were applied for the determination of CPM content in three registered CPM tablets. As a result, the first derivative spectrophotometry method obtained the $\delta A / \delta \lambda$ of tartrazine in matrix tablet was nearly zero at the wavelength of $232 \mathrm{~nm}$ and did not interfere with the $\delta A / \delta \lambda$ of CPM. The selective mobile phase for separation of CPM from tartrazine using HPLC method was a mixture of phosphate buffer $\mathrm{pH} 4$ and methanol $(60: 40 \mathrm{v} / \mathrm{v})$ with a flow rate of $1 \mathrm{ml} / \mathrm{min}$. The CPM separated from tartrazine and other peaks in sample(s) with Rs of $>1.5$ The linearity, accuracy, and precision of these two methods fulfilled the reference requirement. No significant difference observed between the CPM content in artificial tablets when analyzed using first-derivative spectrophotometry and HPLC method. The concentration of CPM in one registered tablet that had been assayed using spectrophotometry, HPLC and the standard method was not significantly different. As a conclusion first-derivative spectrophotometry and HPLC method were valid for the determination of CPM in a tablet containing tartrazine. However, the first-derivative spectrophotometry method was more efficient than HPLC.
\end{abstract}

KEYWORDS: Chlorpheniramine maleate; tartrazine; UV-spectrophotometry; HPLC; method validation.

\section{INTRODUCTION}

Most of chlorpheniramine maleate (CPM) tablets use tartrazine (FD\&C yellow no. 5) as a yellow coloring agent. CPM tablet is one of over-the-counter (OTC) medicines that rarely marketed with a color other than yellow. CPM is the first generation of antihistamine (AH1) that relieves most symptoms associated with allergic rhinitis or hay fever. CPM has mild sedative action and slight anticholinergic activity [1].

CPM is a basic substance that forms a salt with an equimolar portion of maleic acid (Figure 1A) [2], whereas tartrazine is a trisodium salt of dye anion (pKa 9.4) (Figure 1B) [3]. Tartrazine and CPM are polar substances that have similar solubility in water, methanol, $0.1 \mathrm{~N} \mathrm{NaOH}$ and $0.1 \mathrm{~N} \mathrm{HCl}$, which are the solvent use to extract CPM from the tablet. The presence of tartrazine in CPM tablet solution suspected to interfere with the CPM determination. The tartrazine interference in the CPM determination in tablet dosage form not reported yet.

The official procedure for CPM determination in the tablet dosage form is UV-spectrophotometry after tedious extended extraction process using hexane $[2,4,5]$. In addition, CTM determination in extended-release capsule dosage form [2] or in the mixture with other compounds in common cold relieving drugs such as pseudoephedrine [2], paracetamol, caffeine [6] and dexamethasone [7] is using high performance liquid chromatography (HPLC).

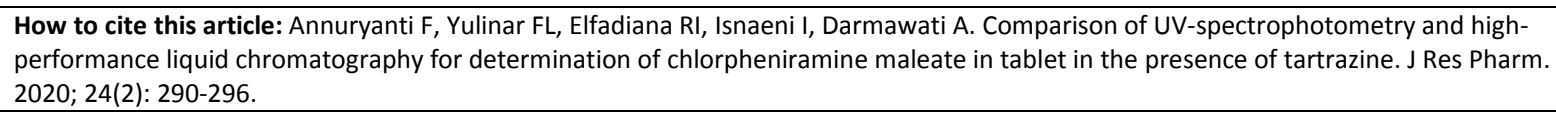


The overlapping of UV-spectra between CPM and tartrazine makes the CPM determination using direct UV-spectrophotometry without preceded by tartrazine separation is implausible. In the previous study, the combination the UV-spectrophotometry with multivariate analysis has been done for CPM determination in a mixture with dexamethasone and propylparaben $[7,8,9]$. While CPM determination using HPLC methods [2][9] needed a relatively long retention time $\left(\mathrm{t}_{\mathrm{R}}\right)$ and caused the peak tailing of tartrazine.

The aim of this study was to obtain a simple, efficient and valid method for the determination of CPM in a CPM tablet containing tartrazine. The valid proposed methods would be compared with the compendial method for the determination of CPM in three registered CPM tablets coded $\mathrm{A}^{\circledR}, \mathrm{B}^{\circledR}$, and $\mathrm{C}^{\circledR}$.<smiles>CN(C)CCC(c1ccccc1)c1ccc(Cl)cc1</smiles>

(A)

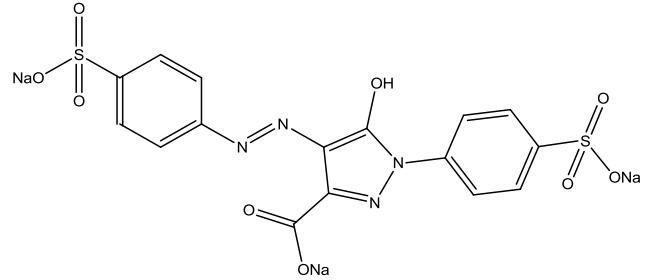

(B)

Figure 1. Structure molecules of chlorpheniramine maleate (A) and tartrazine (B).

\section{RESULTS AND DISCUSSION}

\subsection{Validation method}

\subsubsection{Selectivity of the first derivative spectrophotometry}

The overlapping UV spectra profile of standard CPM and tartrazine was depicted in Figure 2. A higher absorbance value of CPM will be obtained if the same concentration of CPM is in the mixture with tartrazine. This is a determined error in CPM analysis. Therefore, the first-derivative spectrophotometry method was studied as a solution method. By first derivative program, the $\delta A / \delta \lambda$ of tartrazine (also a tablet matrix containing tartrazine) was almost zero at the $\lambda$ of $232 \mathrm{~nm}$. While the $\delta A / \delta \lambda$ of CPM in a mixture with tartrazine was relatively the same as $\delta \mathrm{A} / \delta \lambda$ of $\mathrm{CPM}$ without tartrazine. This means that tartrazine does not interfere with the value of $\delta A / \delta \lambda C P M$ at $232 \mathrm{~nm}$ anymore. The first derivative $(\delta A / \delta \lambda)$ spectra profile of standard $\mathrm{CPM}$ and tartrazine was shown in Figure 3. The $\delta \mathrm{A} / \delta \lambda$ value at $232 \mathrm{~nm}$ was selective for CPM in a mixture with tartrazine.

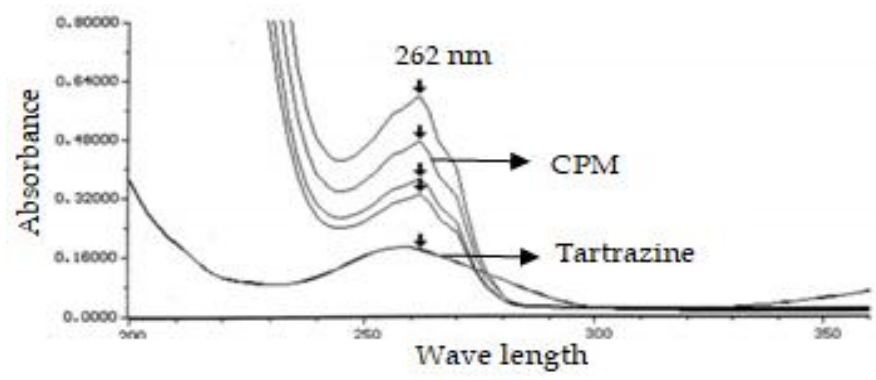

Figure 2. The UV spectra of (20.0- 40.0) ppm CPM and 5.0 ppm tartrazine in methanol:water (1:1).

\subsubsection{Selectivity of the HPLC method}

An optimum condition HPLC for the determination of CPM in the presence of tartrazine listed in Table 1. The proposed HPLC method completely separated chlorpheniramine (CP) from other substances in the CPM tablet with resolution (Rs) $>1.5$ as shown in Figure 4 . The standard CPM as maleate salt splitted into maleic acid (MA, $t_{R}$ of 3.3 minutes) and chlorpheniramine (CP, $t_{R}$ of 16.89 minutes) (Figure $4 A$ ). The $p H$ of the mobile phase and organic solvent composition influenced the CPM ionization. The buffer $\mathrm{pH} 4$ causes the MA $(\mathrm{pKa} 1=1.94)$ to be in the ionic form and eluted immediately. Whereas CP as the basic amine $(\mathrm{pKa}=9.47)$ was protonated and eluted later. The spectra of MA and CP were inserted in Figure 4A. 


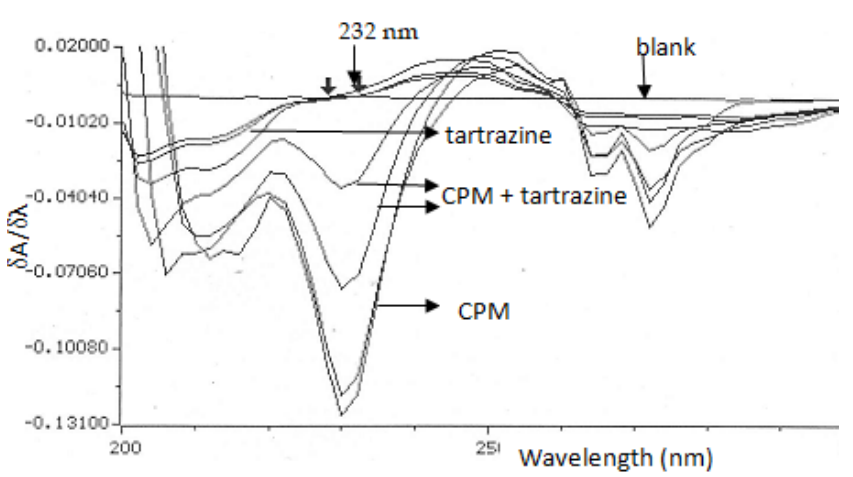

Figure 3. First derivative spectra of standard tartrazine (5.0 ppm, $8.0 \mathrm{ppm}$, and $10.0 \mathrm{ppm})$, a mixture of CPM (9.0 ppm, $18 \mathrm{ppm})$ and tartrazine (5 ppm, $8 \mathrm{ppm})$ and standard CPM (30 ppm).

Table 1. Optimum HPLC condition for determination of CPM in the tablet.

\begin{tabular}{ll}
\hline Condition & Result \\
\hline Mobile phase & buffer phosphate solution $\mathrm{pH} 4$ and methanol of $(60: 40)$ \\
Flow-rate & $1 \mathrm{~mL} /$ minute \\
Injection volume & $20 \mu \mathrm{L}$ \\
Detector & $\mathrm{DAD}$, wavelength of $262 \mathrm{~nm}$ \\
Retention time of CPM & $17.78 \pm 0.27$ minutes \\
Peak purity of CPM & 0.9999 \\
Tailing factor & $1.06 \pm 0.03$ \\
Theoretical plate & $2304 \pm 53$ \\
\hline
\end{tabular}

The tablet matrix containing tartrazine showed two peaks (Figure 4B). At the same time, the chromatogram of the tablet matrix without tartrazine (blank) showed no peak (the picture is not presented) The two peaks in the tablet matrix suspected to come from tartrazine and its impurity (Tar I and Tar II). The UV spectra of Tar II looks like tartrazine spectra with a maximum wavelength of $425 \mathrm{~nm}[3,11]$, whereas the first peak of tartrazine (Tar I) was overlapped with maleic acid peaks of CPM. All substance in tablet matrix eluted before CP and completely separate.

The chromatogram of the artificial CPM tablet (a mixture of tablet matrix and standard CPM) showed in Figure 4C1. This chromatogram profile was identical to the chromatogram of registered CPM tablet sample coded $A \AA$ and $C \AA$. While the registered $C P M$ sample tablet coded $B \AA$ showed four peaks (Figure 4C2). However, the CP peak of all samples separated from other nearest compound peaks with Rs of $>1.5$. The intraday instrument precision of $\mathrm{CP}$ area was $0.82 \%$. The selectivity of HPLC was fulfilling the reference recommendation $[12,13]$.
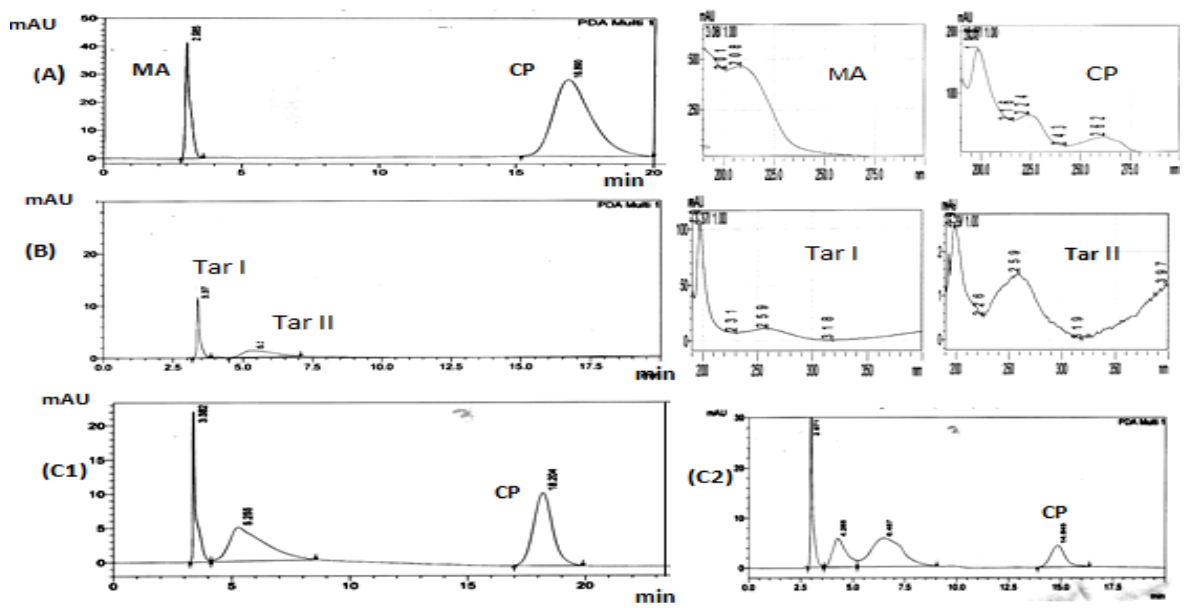

Figure 4. Chromatogram profile of $\mathrm{CPM}$ standard, inserted with MA and $\mathrm{CP}$ spectra (A), tartrazine and the impurities (B), artificial CPM tablet (C1) and CPM tablet sample coded $\mathrm{B} \circledast(\mathrm{C} 2)$. 


\subsection{Linearity}

The first derivative spectrophotometry obtained linearity parameter $\left(R^{2}\right)$ of CPM was 0.999 in the CPM concentration range of (10-40) ppm. The linear equation was $\mathrm{Y}=\left(-3,331 \times 10^{-3}\right) \mathrm{X}-2,487 \times 10^{-3}$ and function's standard deviation (Vxo) was $1.33 \%$.

The HPLC method obtained the linearity parameter $\left(\mathrm{R}^{2}\right)$ of CPM in concentration range of (10-80) ppm was 0.999 . The linear equation was $Y=12526 \mathrm{X}+19662$ and function standard deviation (Vxo) was $2.45 \%$. It can be concluded that the two method fulfilled the reference requirement $[12,13]$ for linearity test.

\subsection{Accuracy and precision}

A comparison of the accuracy and precision between the first derivative spectrophotometry and HPLC for CPM determination in an artificial tablet presented in Table 2.

The independent $t$-test using SPSS obtained no significance differences between the mean value of both methods ( $p=0.492>0.05$ ). To sum up, the first derivative spectrophotometry and HPLC method were accurate and precise for CPM determination in tablet within the presence of tartrazine. As reference requirement for the accuracy and precision were $98-102 \%$ and $2 \%$, respectively [12,13].

Table 2. The accuracy and precision of the first derivative UV spectrophotometry and the HPLC method for CPM determination in the artificial tablets.

\begin{tabular}{ccc}
\hline \multirow{2}{*}{\begin{tabular}{c} 
CPM relative concentration in each $\begin{array}{c}\text { CPM recovery (\%) } \\
\text { artificial tablet }\end{array}$ \\
\cline { 2 - 3 }
\end{tabular}} & $\begin{array}{c}\text { First derivative } \\
\text { Spectrophotometry }\end{array}$ & HPLC \\
\hline \multirow{2}{*}{$80 \%$} & 99.81 & 98.20 \\
& 99.01 & 99.47 \\
\multirow{2}{*}{$100 \%$} & 99.82 & 98.08 \\
\hline & 98.24 & 99.69 \\
& 98.68 & 99.35 \\
\multirow{2}{*}{$120 \%$} & 98.11 & 100.67 \\
& 99.47 & 99.39 \\
& 100.41 & 101.28 \\
Average & 100.21 & 100.50 \\
CV & $99.31 \pm 0.01$ & $99.62 \pm 0.93$ \\
\hline
\end{tabular}

\subsection{Determination of CPM in tablet containing tartrazine}

Three registered CPM tablets were analyzed using thin layer chromatography (TLC) prior to CPM determination for tartrazine identification. The TLC results showed that all samples contained tartrazine (data not shown). A comparison of the result of $C P M$ determination in registered tablet $A \circledast, B \circledast$ and $C \circledR$ using official procedure [2], first derivative spectrophotometry and HPLC was listed in Table 3. The official procedure for CPM determination in the tablet was direct UV-spectrophotometry where the CPM absorbance was measured after CPM has been previously separated from tartrazine by liquid-liquid extraction.

The results of CPM determination in sample $A \circledR$ using derivative UV-spectrophotometry was significantly different from the obtained result using reference methods $(P=0.007<0.05)$. This difference may be caused by the zero point selection of $\delta \mathrm{A} / \delta \lambda$ tablet matrix being less accurate. The different composition of the tablet matrix could shift the zero point as the basis for analytical wavelength selection. Therefore, the analytical wavelength must be re-confirmed to obtain the derivative absorbance of the matrix relative zero to the CPM.

Even though the chromatogram profile of tablet sample $B \circledR$ (Figure $4 C 2$ ) presented an unkown peak after tartrazine, the result of CPM determination in sample $B \circledast$ was not significantly different among the three methods used (oneway anava, $\mathrm{P}=0.421>0.05$ ). It can be concluded that the derivative spectra of the unknown analyte in sample $B \circledast$ was not affected the CPM derivative absorbance at the zero point.

The results of CPM determination in sample $C \circledR$ using HPLC was significantly different compared with the result of the official methods $(\mathrm{P}=0.004<0.05)$. Nevertheless, the CPM content in all registered tablets using all methods fulfilled the reference requirement [2].

Comparison of derivative spectrophotometry and proposed HPLC method indicated that spectrophotometry was more efficient, rapid and reproducible. It was suggested that the derivative 
spectrophotometry could be used for in process control of CPM tablet production or in development of CPM tablet formula in the research development laboratory.

Table 3. Result of CPM determination in registered tablet.

\begin{tabular}{|c|c|c|c|c|c|c|c|}
\hline \multirow{3}{*}{ Sample } & \multirow{3}{*}{ Replicate } & \multicolumn{6}{|c|}{ The CPM content in each registered tablet using the method: } \\
\hline & & \multicolumn{2}{|c|}{$\begin{array}{c}\text { First derivative } \\
\text { Spectrophotometry }\end{array}$} & \multicolumn{2}{|c|}{ HPLC } & \multicolumn{2}{|c|}{ Official } \\
\hline & & $\mathrm{mg}$ & $\%$ & $\mathrm{mg}$ & $\%$ & $\mathrm{mg}$ & $\%$ \\
\hline \multirow[t]{3}{*}{$A \circledast$} & 1 & 3.66 & 91.50 & 3.92 & 98.00 & 3.93 & 98.23 \\
\hline & 2 & 3.64 & 91.00 & 3.88 & 97.00 & 3.75 & 93.78 \\
\hline & 3 & 3.66 & 91.50 & 3.98 & 99.50 & 3.89 & 97.29 \\
\hline Average $A \circledast$ & & & 91.33 & & 98.17 & & 96.43 \\
\hline \multirow[t]{3}{*}{$\mathrm{B} \circledast$} & 1 & 4.02 & 100.5 & 4.07 & 101.7 & 3.93 & 98.23 \\
\hline & 2 & 4.04 & 101.0 & 4.16 & 104.0 & 4.17 & 104.4 \\
\hline & 3 & 4.02 & 100.5 & 4.06 & 101.5 & 3.61 & 90.25 \\
\hline Average $B 囚$ & & & 100.67 & & 102.4 & & 97.63 \\
\hline \multirow[t]{3}{*}{$C \circledR$} & 1 & 3.90 & 97.50 & 4.14 & 103.5 & 3.64 & 91.19 \\
\hline & 2 & 3.88 & 97.00 & 4.17 & 104.25 & 3.67 & 91.74 \\
\hline & 3 & 3.88 & 97.00 & 3.88 & 97.00 & 3.75 & 93.92 \\
\hline Average $C \otimes$ & & & 97.17 & & 101.58 & & 92.28 \\
\hline
\end{tabular}

\section{CONCLUSION}

Based on this study, it could be concluded that the derivative spectrophotometry and modified HPLC methods were valid for determination of CPM in a tablet containing tartrazine. The derivative spectrophotometry was more efficient than HPLC provided the matrix tablet composition is known.

\section{MATERIALS AND METHODS}

\subsection{Materials}

Chlorpheniramine Maleate p.g. (a gift from Interbat Pharmaceutical Industry), tartrazine (a gift from Aditama Raya Pharmaceutical Industry), methanol p.a (Sigma), $\mathrm{KH}_{2} \mathrm{PO}_{4}$ p.a (Sigma), $\mathrm{H}_{3} \mathrm{PO}_{4}$ p.a (Sigma). Placebo tablet containing starch 1500, micro-crystaline cellulose, magnesium stearate of pharm. Grade purity and three commercially registered $C P M$ tablets coded $A \circledR, B \circledR$ and $C \circledR$.

\subsection{Instrument}

UV-Vis Spectrophotometer Hewlett Packard 8452A, HPLC Shimadzu L20-AD with Diode Array Detector (DAD), $\mu$ bondapak C-18 $(10 \mu \mathrm{m}, 300 \times 3.9 \mathrm{~mm})$ column, Soccorex micropipette $(\mathrm{d}=1.0 \mu \mathrm{L})$, Vortex (Genius 3), centrifuge apparatus (EBA20 Hectic), ultrasonic bath (Branson 43510), analytical balance Toledo ( $\mathrm{d}=0,001 \mathrm{mg}), \mathrm{pH}$ meter Ohaus-starter 3000 .

\subsection{05 M Phosphate buffer $\mathrm{pH} 4$}

6.804 gram KH2PO4 dissolved in sufficient 294olüme of water and adjusted with $85 \% \mathrm{H} 3 \mathrm{PO} 4$ to a $\mathrm{pH} 4$ before added the water until $1000 \mathrm{~mL}$ in a volumetric flask. The solution was filtered using membrane filter with a pore of $0.45 \mu \mathrm{m}$.

\subsection{Preparation of standard CPM and tartrazine solutions}

$12.5 \mathrm{mg}$ CPM dissolved in a mixture of methanol: water (1:1) as a solvent. The solution transferred into a $50.0 \mathrm{ml}$ volumetric flask and added the solvent until the marked line. The CPM solution diluted using the same solvent to obtain CPM working solution with a concentration range of (20-40) ppm. The tartrazine standard solutions were prepared by the same manner and diluted to obtain tartrazine working solution in the concentration range of 4-6 ppm.

\subsection{Preparation of CPM tablet matrix}


All the matrix components were mixed homogenously for 100 artificial tablets and stored the matrix powder in a dry container until to be used. Each artificial tablet containing matrix composition as follow: Avicel $102(110 \mathrm{mg})$, micro-crystaline cellulose $(89 \mathrm{mg})$, magnesium stearate $(0.37 \mathrm{mg})$ and tartrazine $(0.50 \mathrm{mg})$. This model composition was adopted from a tablet standard formula [13].

\subsection{Sample preparation for CPM determination by derivative UV spectrophotometry and HPLC}

Twenty CPM tablets were weighted and finely grinded. The average weight of the tablets was determined. The tablet powder was weighted accurately equivalent to $4 \mathrm{mg}$ of CPM to be transferred into a $100 \mathrm{~mL}$ volumetric flask, added with $50 \mathrm{~mL}$ methanol and shaking in an ultrasonic bath for 15 minutes. Finally, distilled water was added up to the marked line, and shake homogenously. The supernatant was filtered using membrane filter with pore of $0.2 \mu \mathrm{m}$. This solution contains $\mathrm{CPM}$ of $40 \mathrm{ppm}$ and ready to analyze with spectrophotometer or HPLC.

\subsection{Validation of the method}

\subsubsection{Selectivity of the first derivative spectrophotometry method}

The first derivative spectra of standard solutions of CPM, tartrazine and tablet matrix were overlaid at the wavelength range of $200-400 \mathrm{~nm}$. As a blank solution was a mixture of methanol: water (1:1). The wavelength where $\delta A / \delta \lambda$ of tartrazine almost zero was determined. When $\delta A / \delta \lambda$ of tartrazine was zero, the measured $\delta A / \delta \lambda$ was $C P M$. At that selected wavelength the increase or decrease $\delta A / \delta \lambda C P M$ will be linear with the increasing CPM concentration.

\subsubsection{Selectivity of the HPLC method}

Operational conditions were selected based on the requirements of the selectivity parameter as follows: resolution (Rs) between $\mathrm{CP}$ and tartrazine was $\geq 1.5$, theoretical plate $(\mathrm{N})>2000$ and $\mathrm{CPM}$ tailing factor $\leq 2$. To meet the requirements of the selectivity, variation in operational conditions such as mobile phase composition and the flow rate were carried outs. The ratio of phosphate buffer solution and methanol as mobile phase modified in the range of (75:25)-(60:40), the $\mathrm{pH}$ variation of phosphate buffer ( $\mathrm{pH} 3$ to 4 ) and the mobile phase flow rate range of $(0.8-1.5) \mathrm{mL} /$ minutes.

The instrument precision acquired by 6 times injection the CPM solution at the same operational condition. The relative standard deviation of the $t_{R}$ and area of CPM should be not more than $2.0 \%$ [2].

\subsubsection{Linearity test}

The five CPM working solutions in the range concentration of (10-80) ppm were measured their signal using UV spectrophotometer and HPLC to obtain the linear relationship equation $(\mathrm{Y}=\mathrm{bx}+\mathrm{a})$. The AOAC requirement [12] for linearity are the coefficient of correlation $(\mathrm{r})$ more than 0.99 and standard deviation of function $\left(\mathrm{V}_{\mathrm{xo}}\right)$ not more than $5 \%$.

\subsubsection{Accuracy and precision}

Each standard CPM of $3.2 \mathrm{mg}$, $4.0 \mathrm{mg}$ and $4.8 \mathrm{mg}$ in a different $100 \mathrm{~mL}$ volumetric flask was added with $200 \mathrm{mg}$ matrix powder. A mixture of standard CPM and matrix powder was processed according to step 4.6. The signal of the solution was measured using UV spectrophotometer and HPLC. Each mixture was processed in 3 times replication.

\subsection{Assay of CPM in tablet using official procedure $[2,4]$}

Not less than 20 tablets were weighed and finely powdered. A portion of powdered tablets equivalent to $4 \mathrm{mg}$ of CPM was weighed accurately and transferred to a $125 \mathrm{~mL}$ separator. Twenty $\mathrm{mL}$ of dilute $\mathrm{HCl}$ $(1=100)$ was added to the separator and shaken vigorously for 5 minutes, and then added with $20 \mathrm{~mL}$ hexane, shaken carefully, and the acid phase was filtered into a second $125 \mathrm{~mL}$ separator. The hexane phase was shaken with two $10 \mathrm{ml}$ portions of dilute $\mathrm{HCl}(1=100)$. Each portion of acid was filtered into the second separator, and the hexane phase discarded. The acid extract was added with $10 \mathrm{~mL}$ of $1 \mathrm{M} \mathrm{NaOH}$ and $50 \mathrm{~mL}$ hexane, shaken carefully. The aqueous phase transferred into the third $125 \mathrm{~mL}$ separator containing $50 \mathrm{~mL}$ hexane. The third separator was shaken carefully, and the aqueous phase discarded. The two hexane solutions washed, in succession, with a single $20 \mathrm{~mL}$ portion of water, and the water discarded. Each of the two hexane solutions extracted with the 20,20 and $5 \mathrm{~mL}$ portion of dilute $\mathrm{HCl}(1=100)$. The acid extracts were combined in a $50 \mathrm{~mL}$ 
volumetric flask, diluted to volume, and mixed. The CPM absorbance was measured at the wavelength of 264 nm using UV spectrophotometer.

The standard solution was prepared by accurately weighing $40 \mathrm{mg}$ of CPM standard to dissolve in 200.0 $\mathrm{mL}$ of dilute $\mathrm{HCl}(1: 100)$ and treated $20.0 \mathrm{ml}$ of this solution in the same manner as the solution of the portion tablet taken.

This procedure involves a long extraction process before CPM absorbance measured by direct UV spectrophotometry. The result of CPM determination using the official procedure used as a reference in compares with the results of CPM determination using derivative UV spectrophotometry and HPLC.

Acknowledgements: This study was supported by funding and facility of The Faculty of Pharmacy of Universitas Airlangga.

Author contributions: Concept - A.D., F.A., I.I.; Design - A.D., F.Y., R.E.; Supervision - I.I., A.D, F.A.; Resources - I.I., A.D., F.A.; Materials - A.D., F.A., I.I.; Data Collection and/or Processing F.Y., R.E., A.D.; Analysis and/or Interpretation - A.D., F.A.,I.I.; Literature Search - A.D., I.I, F.A.; Writing - A.D., I.I, F.A.; Critical Reviews - F.A., F.Y., R.E., I.I., A.D.

Conflict of interest statement: The authors declared no conflict of interest in the manuscript.

\section{REFERENCES}

[1] Remington, The Science and Practice of Pharmacy, twenty second ed., Pharmaceutical Press, London, ENG, UK, 2013.

[2] USP 39/NF 34 Chlorpheniramine maleate tablets. In: United State of Pharmacopoeia 39/National Formulary 34 . (Eds). The United state Pharmacopoeial Convention, Rockville, 2014, pp. 312-316.

[3] Tartrazine, 82nd JECFA-Chemical and Technical Assessment (CTA) 2016. JECFA-Chemical Tech Assess. http://www.fao.org/3/a-br567e.pdf (accessed on 17 October 2018).

[4] Farmakope Indonesia V, Klorfeniramin Maleat, DepKes RI, Jakarta, JKT, ID, 2014.

[5] British Pharmacopoeia, Chlorpheniramine Maleate, The Stationary office, London, ENG, UK, 2016.

[6] Acheampong A, Gyasi WO, Darko G, Apau J, Addai-Arhin S. Validated RP-HPLC method for simultaneous determination and quantification of chlorpheniramine maleate, paracetamol and caffeine in tablet formulation. Springerplus. 2016; 5: 625. [CrossRef]

[7] Darwish HW, Metwally FH, El Bayoumi A. Development of three methods for simultaneous quantitative determination of chlorpheniramine maleate and dexamethasone in the presence of parabens in oral liquids. Trop J Pharm Res. 2015; 14(1): 153-161. [CrossRef]

[8] Darwish HW, Metwally FH, El Bayoumi A. Discrete wavelet transform-partial least squares versus derivative ratio spectrophotometry for simultaneous determination of chlorpheniramine maleate and dexamethasone in the presence of parabens in pharmaceutical dosage form. Trop J Pharm Res. 2015; 14(5): 859-867. [CrossRef]

[9] Kaura AK, Gupta V, Kaura M, Roy GS, Bansal P. Spectrophotometric determination of Chlorpheniramine Maleate and Phenylpropanolamine Hydrochloride by "two wavelengths method". J Pharm Res. 2013; 7(5): 404-408. [CrossRef]

[10] Antakli S, Nejem L, Katran S. Simultaneous determination of tartrazine and brilliant blue in foodstuffs by spectrophotometric method. Int J Pharm Pharm Sci. 2015; 7(6): 214-218.

[11] AOAC International, Official Methods of Analysis of AOAC International, AOAC International, Rockville, MD, US, 2012.

[12] Yuwono M, Indrayanto G. Validation of chromatographic methods of analysis. In: Brittain Harry G. (Eds). Profiles of Drug Substances,Excipients and Related Methodology. Elsevier BV, Netherlands, 2005, pp. 243-259.

[13] Niazi SK. Handbook of Pharmaceutical Manufacturing Formulation: Compressed Solid Formulations, second ed., Informa Healthcare, New York, NY, US, 2004. 